Theories \& Applications, the International Edition

Printed Version : (ISSN 2090-5262)

Online Version : (ISSN 2090-5270)

November 2014, Volume 4, No. 3 Pages (30- 39)

\title{
The Effect of Using Complex Training in Improving the Values of a Number Biomechanics Variants and Explosive Legs Muscles Power of Volleyball Women Players (Jumping Serve).
}

\author{
Dr. Ahmed Mohamed Mohamed Abd Elgayed
}

Assistant Professor, Training and Kinematics Department Faculty of Physical Education, Bortsaeed University, Egypt.

\section{Dr. Marwa Ahmed Fadl Kholif}

Lecturer, training and kinematics department, Faculty of physical education for girls- Alexandria University, Egypt.

\begin{abstract}
The Volleyball sports that you need to prepare special physical addition to the preparation skills and tactical and psychological. . And is the great development of performance skills and especially jump where the transmission performance in a manner jump ( transmitter overwhelming ), which is one of the attacking skills of the team in addition to the skill of beating overwhelming that All players must be on the mastery of all the centers. They also need to force jumped high, as well as bulwark which needs to force jump to the increasing trend towards sporting achievement, to pay scientists to study many of the training methods and in which they can make a positive impact on performance, and is a training compound one of these methods, which have attracted attention in recent times. And has become a training compound practiced widely in the field of sports, to being a training strategy that integrates both weight training and exercises Albleomterc, and became Recommended in the development of the ability of muscle and achieve sporting achievement and when the muscle work according to two two training different is the training boat was launched on training using weightlifting and training Albulaomitri in the same module name (training compound (This type of training allows for a high load than permitted by training Albulaomitri Mnfredaa and thus help to take out as many as possible of the ability.
\end{abstract}

In this sense he found it necessary to develop and improve explosive power in the muscles of the two men 's players volleyball where it was noted the presence of a low level of physical performance for this ability through observation inhalers for the players during the performance through tests of physical performance capacity of the explosive to the muscles of the two men by Testing (vertical jump of stability, vertical jump of movement, broad jump of stability), as well as by observing the performance of which requires skill in the first place, the ability to upgrade and payment to the highest point possible to perform the skill in the best picture in the skill transmitter overwhelming.

The aim of the Aldrashthasin explosive power in the muscles of the two men 's players volleyball through the use of training compound, study the effect of the training compound on the development of some mechanical variables affecting the performance skills, was used descriptive analytical approach: "Analysis biomechanical " and was used experimental method system one group using measurement (pre - post) and the community sample core 10 students allocated Volleyball college (Department of Athletic Training and Movement Sciences and was the most important results that the training program composite proposed impact positively in the improvement of the physical attributes for the ability of the explosive to the muscles of the two men, where results showed rates of improvement in physical abilities own lower end was the most important recommendations of the use of the proposed training program to improve the level of physical performance for your players the difference different to the importance of these muscle groups involved in upgrading and payment, use the style of analysis biomechanics to extract variables biomechanical and the use of them and using them to develop training programs in various skills to raise the level of their performance..

\section{Introduction}

$\mathrm{T}$ The renderings art for each game of games linked to the capabilities of physical, especially those with a positive effect on the level of those renderings , every movement of the movements of the player you need while doing Poweouat different - to move one or more parts of the body parts, and requires the performance of the movement to work a muscle a certain magnitude, and that lead the movement at a certain speed and that the bear 's motion performance for a specific time period , and physical abilities essential is that enable the player to perform various motor skills required by the game that exercised properly, as a cornerstone for the arrival of the players to the best athletic levels high are the capabilities necessary for all games. $(15: 82)$

It is known that each game has its elements of physical own and that set it apart from other games, where each sport requires the performance of various movements such as sprint running and bounce and jump and other such movements to perform motor skills and tactical her, because every sport involving a large amount of kinetic models, so the coach must identify the most important physical attributes for these game and that will help the player to good performance, whether or tactical skill efficiently. ( $16: 33$ )

Volleyball is a sport requiring special physical preparation in addition to skills, plans and psychological preparation. 
The significant performance development in particular in jumping, where the serve is performed in jumping (Powerful Jump Serve) and is considered to be one of the offensive skills in a team, in addition the spikes skills that every player has to master in all centers. Volleyball also needs high jump power and the block also needs jump power. During the game the volleyball player may perform sometimes more than (100) jumps per game. This was illustrated in the jumps statistics performed during the 2010Women Volleyball World Cup. This skill requires high durability without relying on oxygen to produce this explosive force; the game may last for three hours and this requires a high level of explosive power. The Plyometric and the resistance exercises are the most important exercises that promote this development movement efficiency in the muscle contraction (5: 12)(4:3).

In principle, the process of developing muscle strength is a continuous process aimed at upgrading sports while some aims to the process of force development for preventive and remedial purposes. Such development is performed to rehabilitate the affected and vulnerable parts to help them perform their natural functions in a quicker way and also prevents or reduces the muscles and joints injuries.

In various sports activities, the muscle strength of the legs plays an efficient role in improving the performance level. We cannot find one sport where the muscle strength of the two legs does not represent an important aspect of their training and performance.

That the growing trend towards athletic achievement, prompted scientists to study many of the training methods and in which they can make a positive impact on performance, and training complex is one of these roads that have attracted attention in recent times. The training has become composite practiced widely in the field of sports, and for being a strategic training integrates both weight training and exercises Albleomterc, and became Recommended in muscle development ability and achieve athletic achievement.

Where confirms Brad McGregor Brad McGregor (2006), that the training compound is one of the ways modern training in the field of sports and studies on their effects physical and physiological on youngsters and adults differ in their results, and it is due to the different way addressed in the sports field, and that the training compound is merger between weight training and exercises Albleomterc in the same module . (20)
Divides Dyothi and others Duthie, et al. (2002) training patterns used by athletes through the link between exercise and weightlifting Albleomterc to:

1. Training of traditional Traditional Training: It uses the groups Bleomterc groups followed by weights

2. Training compound Complex Training: It uses the weights followed by groups Bleomterc groups in the same module .

3. Training anisotropic Contrast Training: It uses the rotation between the group and the group Bleomterc weights . $(24: 530-538)$

In the opinion of William Laibin William Ebben (2003 m), that training compound became practiced widely in the field of sports, to being a training strategy that integrates both weight training and exercises Albleomterc, and became Recommended in the development of the ability of muscle and achieve sporting achievement . (28)

Both the Aboualala Abdel Fattah (1997), Abdul Aziz Tiger and Nariman al-Khatib (2000), IPN and others Ebbin et all (2000) that the training compound is a weights training strongly high directly followed by exercises Albleomtry in order to improve the status of physical and one is the ability of muscle , and lead the group's first and then weightlifting groups Albleomtry for the same muscle group in a series of training similar mechanically . (1:136), (12:114), (11: $113),(22: 538)$

Also known as a training boat training which uses the groups training with weights, followed by training groups Bleomtria for the same muscle group . "(24: 53)

Refers Talha Hossam El Din (1997), when he is muscular work according to two two training different be training compound was launched on training using weights and training Albulaomitri in the module itself the name of the training compound (This type of training allows for a high load than permitted by training Albulaomitri solo and thus help to take out as many as possible of the capacity) .

And that regular training using weights for six weeks leads to increase the height of vertical jump by $(3.3 \mathrm{~cm})$ and training Albulaomitri for the same period leads to an increase of $\$(3.8) \mathrm{cm}$ while training compound for both types for the same period leads to an increase of $(10.7 \mathrm{~cm})$ $(9: 16, .90)$. 
Table 1

Analysis results of four games during the Premier Women League competitions

\begin{tabular}{|c|c|c|c|c|c|c|c|c|}
\hline & \multicolumn{4}{|c|}{ Spikes } & \multicolumn{4}{c|}{ Power Serve } \\
\hline Period & Success. & Percent.\% & Fail & Percent.\% & Success. & Percent.\% & Fail & Percent.\% \\
\hline First Period & 52 & 76.5 & 16 & 23.529 & 92 & 95.83 & 4 & 4.17 \\
\hline Second Period & 52 & 72.2 & 20 & 27.778 & 80 & 90.91 & 8 & 9.09 \\
\hline Third Period & 48 & 66.7 & 24 & 33.333 & 72 & 85.71 & 12 & 14.29 \\
\hline Fourth Period & 44 & 55.0 & 36 & 45.000 & 64 & 84.21 & 12 & 15.79 \\
\hline Fifth Period & 40 & 55.6 & 32 & 44.444 & 48 & 75.00 & 16 & 25.00 \\
\hline Game & 244 & 63.5 & 140 & 36.458 & 356 & 87.25 & 52 & 12.75 \\
\hline
\end{tabular}

As shown in table (1) if we compare the results of the successful spikes during the five periods of the game : the success rate in the first period amounted to $76.5 \%$, the third period $72.2 \%$ in and $55.6 \%$ in the fifth period. As for the powerful serve, the success results showed an overwhelmingly rate amounting to $95.8 \%$ in the first period, $85.7 \%$ in the third period and a success rate of $75 \%$ in the fifth period. Such results reflect the decline in performance from the first period of the game until the fifth.

Therefore, it was found that it is necessary to develop and improve explosive legs muscle of the women volleyball players. One can observe that there is a reduction of the physical performance level of this capacity through the codified observation of the players during the performance. This can be observed through physical performance tests for explosive muscles power (vertical jump from immobility, vertical jump during mobility and broad jump movement from immobility), as well as the observation of skill performance which mainly and foremost requires the ability to rise and push to the highest point possible to perform the skill in its best configuration and that during the powerful serve.

Hence the importance of the problem of current researchers to find out the extent of the impact of the use of the training compound in improving the values of some variables biomechanical and explosive power in the muscles of the legs of the players, volleyball and evaluation of this method through variables biomechanical capabilities of the explosive to the muscles of the two men 's players volleyball , which called for researchers to carry out this study.

\section{Objective of the research:}

Is determined by the overall objective of the research to identify the extent of the impact of the effect of the use of the training compound in improving the values of some biomechanical variables and explosive power in the muscles of the two men 's volleyball players through .

1. Improve the explosive legs muscle of the volleyball women players through the use of Complex Training
2. Study the impact of Complex Training on developing some mechanical variables affecting the skill performance.

\section{Research Hypothesis:}

1. Functional statistics differences exist between the "Pre and Post measurements" in some of the Biomechanical variants values associated with kinetic performances of the explosive muscles.

2. Functional statistics differences exist between "Pre and Post measurement" in the special physical variables in the explosive capacity of the legs muscles.

\section{Studies of reference:}

1. study Ashraf Abdel- Aziz Ahmad ( 2003) (3 ), entitled "The Impact of the use of weights training and Albleomtry on the development of the ability of muscle and the development of the performance level of some of the attacking skills of soccer players " , and reached the sample (40) for the player of the first class, the experimental method is designed three experimental groups and one control group, and the results indicated the presence of significant differences in favor of the three experimental groups according to the order (set weights and Albleomtry together and then set weights then set Albleomtry ) for the control group in favor of telemetric

2. A study on the Carp Ibrahim conducted a study in 2004 (14), entitled The effect of using the training compound in the manner youthful low-intensity in the rehabilitation of injured athletes weak musculature of the lower limbs was the goal of research is to use the exercise vehicle of exercise weights and Albleomtrick in the rehabilitation of some of the injured athletes weak musculature of the lower limbs the total sample size of the study (10) athletes complain of muscular weakness in the lower limbs researcher has used experimental method deviation measurement tribal posttest for the experimental group and one was the most 
important results experience positive in the rehabilitation of injured athletes and sent them back to the stadiums once again that the use of weights training and Albleomtrick style training compound way youthful performance in lowintensity exercises for lower limbs accelerates the process of muscle development came the most important recommendations of the need to use the qualifying program prepared in the search by the coaches and staff in fitness centers and rehabilitation to reduce the incidence of muscle weakness of the lower limbs in athletes and nonathletes .

3. Study Wilson, Murphy, age (Wilson \& Murphy \& walsne (1997) (29) entitled "The advantage of weight training exercises Albleomterc and its impact on the ability of the athlete ," and amounted to sample 30 students 16-18 years old , use the experimental method is the same group , and noted results and weightlifting exercises that have Albleomtry Tathiraijaa at the level of muscular strength of an athlete .

4. Study Radcliffe and Radcliffe (Radcliffe and Radcliffe (1999) (27) entitled "Impact of training compound Party Lower on the ability of muscle to volleyball player ," and reached the sample ( 19) for the player, use the experimental method groups experimental, and results indicated improved vertical jump for the experimental group from the control group

5. Study: Factor and others (Factour et el (2000) (25) called the study "Evaluation of training Albleomtry and training weights on the strength of the muscles of the two men and the completion of vertical jump " and amounted to sample the study (14) for the player, use the experimental method with the two groups, and the results indicated the development of improved strength and vertical jump exercises using weights and Albleomtry .

6. Study your Bnalberho Duke S. Beneliyohu (2002) (2) Aanoan study training with weights and Albleomtry and effectiveness of the performance of the athlete to develop the ability of muscle and objective of the study study to know the extent of the impact of training with weights and Albulaomitri to develop the capacity of muscle for the athletes were using the experimental method and amounted to a sample (15) students from secondary study showed the following results improved the ability of the muscle group training with weights and Albleomtry by $11 \%$ while the amount of improvement in the ability of the muscle group used weights training by $3 \%$.

Varied reference studies in different sample size, and adopted studies on the players practicing for the game and again relied on the students, used most of the studies the experimental method, has achieved results of studies differences statistically significant contributed to the development of the performance level of the research sample physical and the skill through the use disparate training compound ( weightlifting, Albulaomitri ) except that in the limits of science researchers have not touched any of these references to the use of the training compound from the perspective of Byumkaniki which prompted the researchers to conduct the current study and learn about the impact of the use of the training compound in improving the values of some variables biomechanical and explosive power in the muscles of the legs of the players Volleyball .

\section{Research Procedures:}

The descriptive analytical protocol was used: "The Biomechanical Analysis", the Experimental Method was applied through the single group system by the using "Pre and Post measurements".

The sample society of the basic and the survey studies were compiled to a high level player of the Egyptian International Women Volleyball team and 10 students majoring Volleyball (Sports Training Department and Kinetic Sciences) to the baseline study.

For the Data collection, the researchers used: a Rasta-Meter device to measure the distance (to the nearest $\mathrm{CM}$.), medical scale to measure the weight (to the nearest $\mathrm{kg}$ ), a measuring tape to measure the lengths of the body's limbs (to the nearest $\mathrm{cm}$ ), a scaled ruler, a Panasonic video camera modelJVC9800 frequency 25 cadre/w, and the analysis program "Win analyze".

The researcher conducted the survey study using twodimensional imaging to identify the basic working muscle groups while the player is performing the skill under this study, this was based on a qualitative and anatomical analysis steps as follows :

I : Break up the skill under study into four main phases:-

Approaching Phase, Jumping Phase, Flight and Shooting Phase, Landing and Follow-up Phase.

II: Identify the working joints during the performance, the movements that occur within, the direction and the extent of movement. Since all the players are right hand shooters, the researcher analyzed the movements of the following joints:

Right foot ankle, right knee, right hip, right hand wrist, right shoulder and right elbow.

III: The Muscular Contraction Type and the muscle groups involved in the production of the movement were selected.

IV: The moments when an angular acceleration in the joint occurs were defined (either by increase or decrease) and the location of impact.

$\mathrm{V}$ : Any extended increase (excessive) in the kinetic joints movement were identified (15: 4-8).

The results of the study survey identified the following: the most important muscle groups involved, the type of muscular contraction and the moments of angular 
acceleration in the joint during the performance of the skill under study.

As per the above mentioned in the survey study and in order that the researcher achieves the research objectives the baseline study was divided into several phases as follows:

Phase 1: The design of the proposed training program based on Anatomic Biomechanics of the muscles working on the lower limb during skill performance and the elaboration of a set of qualitative special exercises for explosive power of the legs.

Phase 2: The researcher applied the proposed program on the basic sample study at the Faculty of Physical Education for Girls - Alexandria University- as per three training units per week, for 8 consecutive weeks. The training session duration was fixed to be (70 minutes).

Formation of the training load of the proposed training program:

The researcher used a training load using the (2: 1) method. This means that it is a high intensity load (less than the maximum) for two consecutive weeks; load will be dropped during the third week (average load). Also, the load degrees correspond to the loads specified in a number of scientific references and reference studies as follows:

Table (2)

composition of load degrees of the proposed training program

\begin{tabular}{|c|c|c|c|}
\hline Load Specs. & Load Level & Nuber of repetitions & Rest Periods \\
\hline Less than the Maximum & $80:$ less than $90 \%$ & $6-10$ times & $2-4$ Minutes \\
\hline Average & $70:$ Less than $80 \%$ & $11-15$ times & $1-2$ Minutes \\
\hline Less than average & $70:$ less than $50 \%$ & $16-22$ times & $1 \mathrm{M}-45 \mathrm{sec}$ \\
\hline
\end{tabular}

$(14: 91)(17: 225)$

Phase III: applying the "Pre measurement" on the Basic sample study by two-dimensional imaging and the measuring of the physical abilities of sample study players.

Phase IV: The proposed training program was implemented based on a set of specific exercises for explosive muscles power during the period from 5/4/2011 to 31/5/2011 where the total training units reached (24 units). Annex (1), (2).
Step V: The apply sample "Post measurement" on the baseline study by two-dimensional imaging and measuring of the physical capabilities of the study sample players.

Presentation and discussion of the results:

The researchers will display the results that have been obtained, based on the goals of research

Table (3)

the arithmetic average and the standard deviation and "t" difference of the "Pre and Post measurements" differences of a number of the Biomechanical variables of the body's centre of gravity of the body of the study sample (Jump) $\mathbf{n}=\mathbf{1 0}$

\begin{tabular}{|c|c|c|c|c|c|}
\hline \multirow{2}{*}{ Variables } & \multicolumn{2}{|c|}{ Pre Measurement } & \multicolumn{2}{|c|}{ Post Measurement } & \multirow{2}{*}{ Difference } \\
\hline & $\mathrm{m}$ & S.d & $\mathrm{m}$ & S.d & \\
\hline CG Speed resultant & 207.7 & 79.1 & 254.3 & 115.8 & $3.027^{*}$ \\
\hline CG Acceleration Resultant & 1285.1 & 426.6 & 1306.3 & 387.2 & 0.139 \\
\hline CG Push Resultant & 43.5 & 16.8 & 54.2 & 25.1 & $3.205^{*}$ \\
\hline CG Force Resultant & 252.9 & 101.4 & 253.0 & 81.1 & 0.003 \\
\hline CG Quantity Movement Resultant & 96.2 & 52.1 & 107.0 & 63.0 & 0.513 \\
\hline
\end{tabular}

* Incorporeal at function 0.05 and value $(v)$ indexed when $0.05=2.14$

Table (3) concerning the Biomechanical variables at the moment of the Jump shows that there are significant differences between the "Pre and Post measurements" in favor of the "Post measurements" of the lower limbs. The differences are represented in the Center of Gravity Speed
Resultant, " $t$ ' value of the differences amounts to (3.026656) and the average (207.6772). The Center of Gravity Push Resultant, " $t$ " of the difference amounts to (3.205094) and the average pt (43.47775). 
Figure 1

illustrates the difference times the average for the two phases of upgrading and payment of the sample under study before and after the application of the program

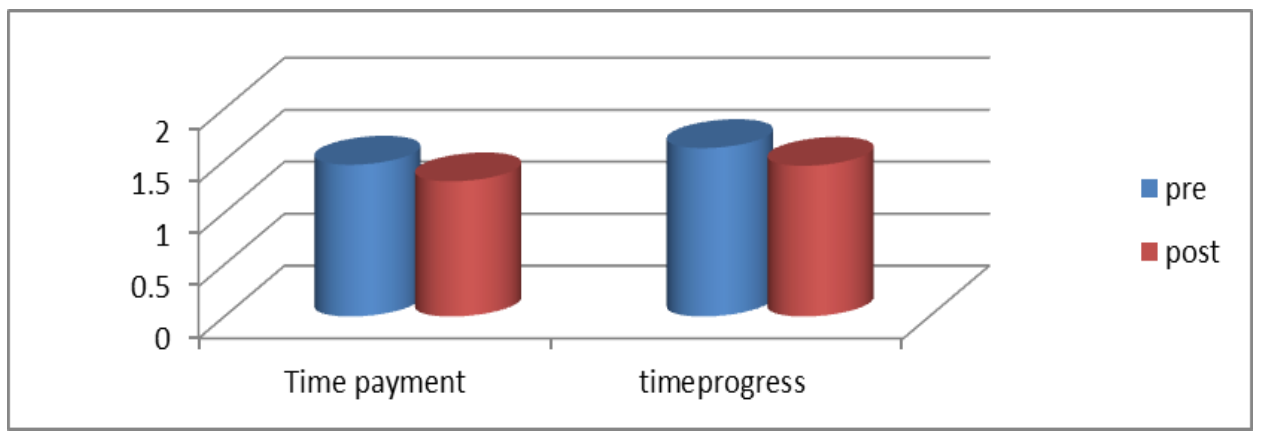

(Figure 2)

the arithmetic average of the pre and posttest measure to some of the biomechanical variables to the body's center of gravity to the sample in the study phase (upgrading)

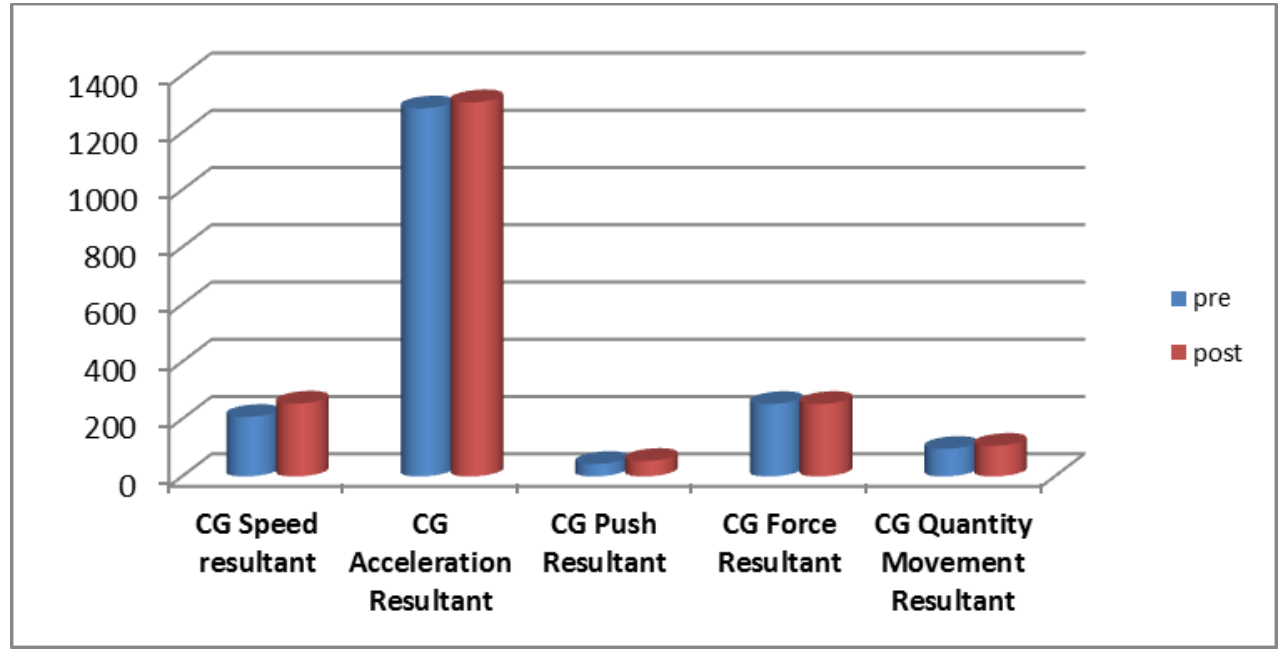

Table (4)

the arithmetic average and the deviation and standard and " $t$ " variances for "Pre and Post measurements" of the Biomechanical variables in the study sample at the Push moment $n=10$

\begin{tabular}{|c|c|c|c|c|c|}
\hline \multirow{2}{*}{ Variables } & \multicolumn{2}{|c|}{ Pre Measurement } & \multicolumn{2}{c|}{ Post Measurement } & \multirow{2}{*}{ Difference } \\
\cline { 2 - 5 } & $\mathrm{m}$ & $\mathrm{S} . \mathrm{d}$ & $\mathrm{m}$ & S.d & \multirow{2}{*}{$4.37^{*}$} \\
\hline CG Speed resultant & 221.62 & 106.58 & 293.97 & 107.04 & 0.10 \\
\hline CG Acceleration Resultant & 1482.74 & 514.11 & 1497.12 & 450.89 & $5.77^{*}$ \\
\hline CG Push Resultant & 52.75 & 18.68 & 59.78 & 20.44 & $3.49^{*}$ \\
\hline CG Force Resultant & 295.57 & 105.08 & 369.81 & 109.93 & $3.19^{*}$ \\
\hline CG Quantity Movement Resultant & 94.59 & 39.68 & 138.78 & 59.79 & 2 \\
\hline
\end{tabular}

* Incorporeal at function 0.05 and value $(v)$ indexed when $0.05=2.14$

Table (4) concerning the Biomechanical variables at the push moment that there are significant differences between the "Pre and Post measurements" in the lower limbs variables in favor of the "Post measurement" represented in the Center of Gravity Speed Resultant, " $t$ " value of the differences amounted to (4.372014) and average amounted to (221.6157). The Center of Gravity Push Resultant, " $t$ " value of the differences amounted to (5.76667) and the average to (52.74556). The Center of Gravity Force
Resultant, "t" value of the differences amounted to (3.485478) and the average to (295.5673). The Center of Gravity of the Amount of Movement Resultant, "t" value of the differences amounted to (3.193185) and the average to(94.59088). 
Figure (3)

the arithmetic average of the tribal and the dimensional measurement of the biomechanical variables in a sample study at the moment of payment

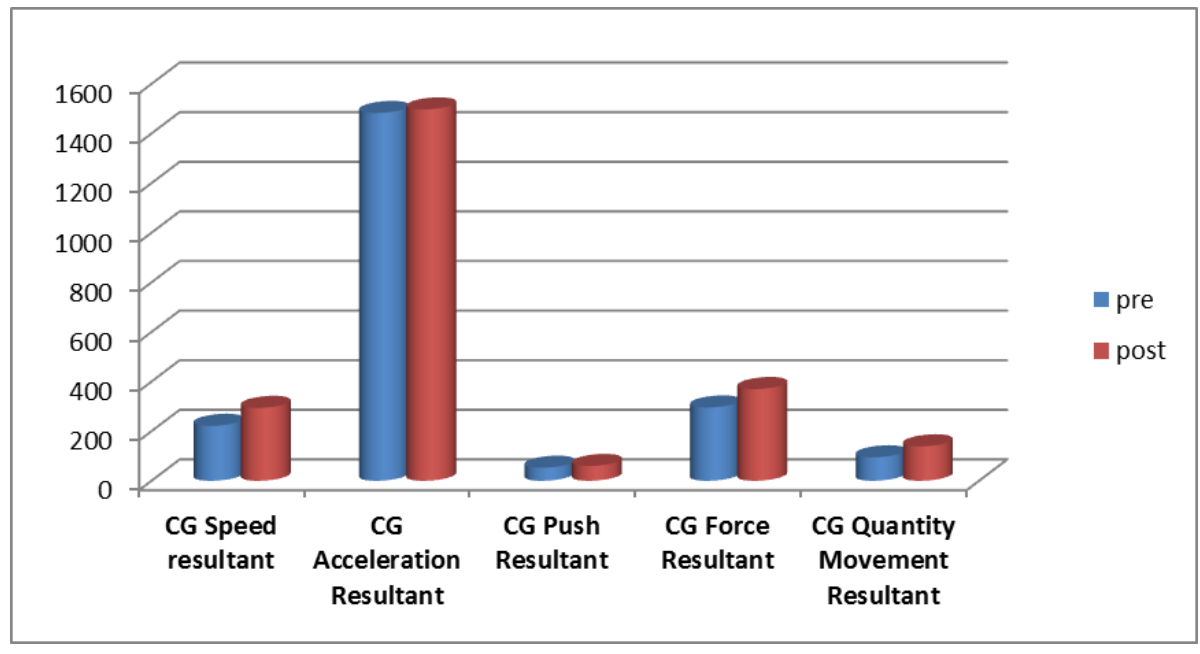

Table (5)

arithmetic average and the standard deviation, " $t$ " differences of the "Pre and Post measurements" of the legs explosive power in the study sample $(n=10)$.

\begin{tabular}{|c|c|c|c|c|c|c|c|}
\hline \multirow{2}{*}{ Variables } & \multirow{2}{*}{$\begin{array}{c}\text { Measure } \\
\text { Unit }\end{array}$} & \multicolumn{2}{|c|}{ Pre Measurement } & \multicolumn{2}{|c|}{ Post Measurement } & \multirow{2}{*}{$\begin{array}{c}\mathrm{T} \\
\text { Difference }\end{array}$} & \multirow[t]{2}{*}{$\begin{array}{c}\text { Improv. } \\
\%\end{array}$} \\
\hline & & M & S.d & $\mathrm{m}$ & S.d & & \\
\hline $\begin{array}{c}\text { Vertical Jump from immobility } \\
\text { Test }\end{array}$ & CM. & 44.4 & 7.57 & 47.08 & 8.34 & $6.16^{*}$ & 5.6 \\
\hline $\begin{array}{l}\text { Board Jump from } \\
\text { immobility Test }\end{array}$ & CM. & 1.67 & 0.21 & 1.90 & 0.20 & $5.95^{*}$ & 12.4 \\
\hline $\begin{array}{c}\text { Jump from mobility (running) } \\
\text { Test }\end{array}$ & CM. & 23.75 & 4.95 & 34.0 & 4.22 & $9.13 *$ & 30.14 \\
\hline $\begin{array}{c}\text { Three jumps forward from } \\
\text { immobility Test }\end{array}$ & CM. & 5.033 & 0.71 & 5.51 & 0.55 & $6.82 *$ & 8.7 \\
\hline
\end{tabular}

* Incorporeal at function 0.05 and value $(v)$ indexed when $0.05=2.14$

Table (5) shows the existence of significant survey differences between the "Pre and Post measurements" in favor of the Post measurement of the sample study in regards to the legs explosive capacity of a sample study. The value of "t" differences varied between 5.95 to 9.13 , the improvement percentage ranged between $5.6 \%$ to $30.14 \%$ between the "Pre and Post measurements" in favor of the Post measurement.

Figure (4)

the arithmetic average of the tribal and posttest measure of the ability of the explosive of the two men in a sample study

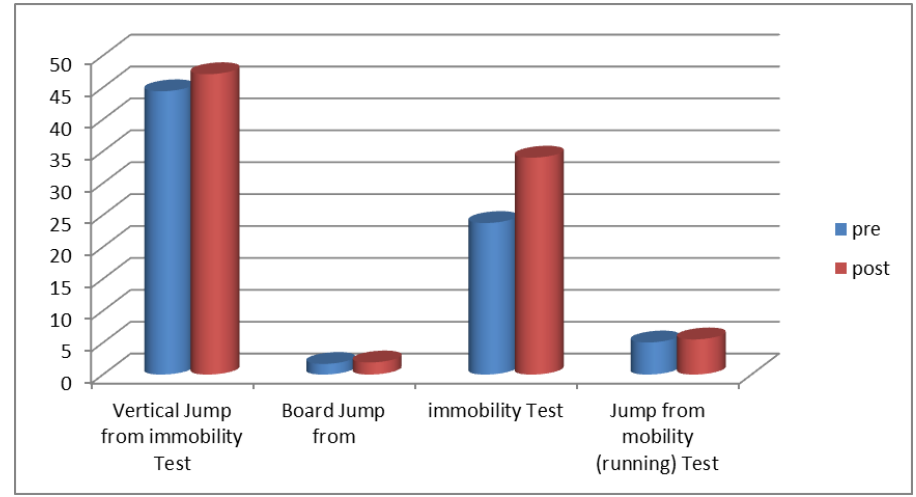




\section{Results}

Table (3), (4), (5) and (Figure 1), (2), (3), (4) and your own biomechanical variables stage and upgrading the payment concern the Plyometric variables for the Jump and Push Phases. The results indicated the presence of improvements in favor of the "Post measurements". Some of the variable values have increased : the Resultant of the Speed of the Center of Gravity and the Resultant of the Push of the Center of Gravity. This is consistent with what was mentioned by "Kamel Abdel Meguid Konsowa and Samir Lotfy said that at the beginning og the Jump Phase, the player must perform a grounding.

To convert the horizontal speed gained from the approach to vertical speed in order to assist it in completing the kinetic duty through braking, this is illustrated by the increase in the vertical speed during the Jump. The strength and speed of the upper limb to the body during the Jump generating a local internal power that helps to convert this horizontal force to the vertical to gain maximum vertical distance after the Jump (21: 106).

At this stage, the lower limb alterations are very importance in view what it acquires as reaction force from the ground to perform a height jump to reach the maximum possible height in next stage.

This consists with what was mentioned by Gamal Aladdin as he demonstrates that the BMI is a measure of the inertia of the body in transitional movement and is the measurable ratio between the amount of applied force and this force requires in acceleration. The acceleration is the rate of change of speed for " $\mathrm{v} / \mathrm{t}$ " $=\mathrm{a}$

\section{$(26: 32)(6: 153)$}

This corresponds to the variables the deeper damping and the push. This is consistent with what Gamal Malash, Hussein Mardan Omar and Adel Turki Hassan mentioned that the importance of grounding lies in the preparation to redistribute the energy from the horizontal direction to the vertical direction in order to benefit from the resultant of the horizontal velocity and convert it to vertical velocity to be consumed during the Jump phase. (19:116)

This is specially shown in the time variable where the results showed that there is differences in the time variable in favor of the "Post measurement" in Jump and Push where time decreased as a result of Ballistic exercises used to develop the strength quality with the speed of the legs as well as variables and speed resultant force and push of the Body's Center of gravity where physical characteristics tests showed statistical differences for the "Post measurements" in the vertical jump test from Mobility or immobility and three forward jumps where the improvement result were (5.6\%), (30.09\%) and (8.7\%) respectively. Such results concur with what Habib Tahir mentioned : the development of the mechanical capacity of the legs muscles is of great importance in achieving Biomechanical conditions for the skill performance. Also, the jumping phase plays an important role in preparation operation for the pushing in terms of the contraction of the lower limb muscle by a portion that will allow the player to convert this energy into a propulsive upward force $(7: 5)$.

Also the above agrees with what Kamel Konsowa and Samir Lutfi mentioned : that incase that the push is performed by the two legs from mobility, the body acceleration in the horizontal direction begins to decrease $y$, at the moment of grounding, accordingly the horizontal speed composite decreases to the greatest possible extent till the body rushes upwards (17: 116).

This illustrates the importance of the push moment in the skill performance, and this is shown in the push, speed and amount of movement variables. This agrees with what was mentioned by both Ahmed Fouad El shazly and Sawsan Abdul Moneim and others and Talha Husam Eldin : that whenever the push was close to the vertical axis (vertical) the push will be powerful which will affect the flight time and thus achieving the greater vertical displacement combination. Also the technical performance of the skills that have higher jump and push if correctly performed will have great effects to increase the momentum which in turn will help to increase the uplifting of the body, and whenever the push angle is close to the vertical axis (vertical) the stronger the push which will increase flight times during the flight and shooting stages i.e. whenever the push angle is larger the longer the flying time is "increase flight time".(2)(6)(10).

\section{Conclusions:}

Within the study sample, the used method, the devices and instruments used to collect the data collection, and in the light of statistical indexes, the presentation and the discussion of the results, the researcher was able to reach the following conclusions:

1. The proposed Complex Training Program and a positive influence in the improvement of the physical qualities of the explosive capacity of legs muscles. The results showed a rate of improvement in the physical capacities of the lower limbs

2. The use of Kinetic Analysis for various athletic skills was one of the most important indicators of the validity and accuracy of the performance evaluation and the elaboration of a skill training program aiming to upgrade the level of skill performance. This was owed to the accurate Biomechanical analysis results which gave a high objective rate when developing the training program.

3. The reliance on anatomical qualitative analysis shows how to develop specialized exercises for skill performance to be developed and improved. 


\section{Recommendations}

Based on the findings, the researcher recommends the following:

1. To use of the proposed Training Program to improve the physical performance of players with different teams for these important muscle groups involved in Jump and Push.

2. To use of the Biomechanical analysis method to extract the variables Biomechanical to use and to employ them in the development of training programs covering the various skills to upgrade their performance.

3. To Benefit from the results of this study when performing similar studies.

The need to inform the instructors and staff of the proposed training programs in the area of sports training to use them as a pilot and guide in the training process

\section{References}

1. Abu Ela Ahmed Abdel Fattah : (1997) sports training bases physiological, Dar Arab Thought, Cairo .

2. Abdu Ahmed Khalifa : (1999) some of the variables Elkinmetekih and special physical qualities and the extent of its contribution to the accuracy of the transmission performance landslide in volleyball, Master Thesis , Faculty of Physical Education in Port Said, Suez Canal University .

3. Ashraf Abdel- Aziz Ahmad ( 2003 ) The impact of the use of weights training and capacity development Albleomtry on muscle development and the level of performance of some offensive skills of soccer players, research publication, the Journal of Sports Science

4. impressive Alwan Jawad al-Jumaili : (2004 ) The impact of the use of exercises Albleomterc in the development of muscle strength For the muscles of the two men volleyball players, Institute of Technology, Baghdad

5. Bastawisi Ahmed : 1996) ) Albleomterc in the training of athletics. The second episode, The International Federation of Amateur Athletics , Center for Regional Development, bulletin athletics , Cairo .

6. Jamal AladdinAnd Nahid Anwar pigment : (2007) the foundations of the metrological performance evaluation and physical skills and tactical athletes , facility knowledge, Alexandria .
7. Habib Ali Taher : (2004) the contribution of certain variables mechanical launching the ball in the transmitter overwhelming skill in volleyball , Faculty of Physical Education - University of Babylon - the Republic of Iraq

8. Salahuddin hopper : (1993) to modern scientific bases for the calendar in motor performance , Renaissance Cairo, Egypt

9. Talha Hossam El Din and others : (1997) Scientific Encyclopedia in athletic training . Cairo

10. Adel Abdul Baseer : (1999) sports training between theory and application, the center of the book for publication, Cairo .

11. Abdul Aziz Tiger, Nariman Mohammed Khatib : (1996) Athletic Training - Training weightlifting design programs muscle strength and planning training season, book publishing house, Cairo .

12. Abdul Aziz Ahmad Tiger, Nariman Mohammed Khatib : $(2000 \mathrm{~m})$ physical preparation and training with weights junior in pre- puberty, professors for publication and distribution, Cairo

13. Mustafa Taha on : (1999) Volleyball - History Education - Training - analysis - Law , Dar Al-Fikr Al Arabi , Cairo

14. Ibrahim Ali Carp 2004 ) The impact of the use of the training compound youthful way in low-intensity rehabilitation of injured athletes muscular weakness of the lower limbs Baghdad University, College of Physical Education, Journal of Physical Education Volume XIII - Second Issue

15. Imad Eddin Abu Zaid Abbas : ( 2005 ) Planning and scientific foundations for the construction and preparation of the difference in mass games, theories and applications, the first edition , facility knowledge, Alexandria .

16. Fuad Ahmed Said Burgos : ( 2008 ) anthropometric measurements and their relationship with some elements of fitness as an indicator of the performance skills of basketball players for the class hopes ( 13-16 years) area of Tripoli , Unpublished MA Thesis , Faculty of Physical Education and Sports, Al-Fateh University, Libya Arab Jamahiriya Great Socialist .

17. Full Qansuh Abdul Majeed, Mr. Samir Lotfy : (1993) . Quantitative changes of biomechanical properties during the phase of upgrading the skills of the transmitter and battery overwhelming landslide in volleyball, Journal of Science and Arts of 
Physical Education, the third issue, Assiut University .

18. Mohammed Jaber Briva and charitable diabetes : (2004) . Albyumkaniki qualitative analysis to improve the training process, the Eighth International Scientific Conference for Science Physical Education and Sports, Faculty of Physical Education for Boys, Alexandria University .

19. the success of the Mahdi Shalash et al (1999) An analytical study of some of the variables in the transmitter Elkinmetekih landslide in a game of volleyball, published research, the Iraqi Academy of Physical Education, Iraq

20. Brad McGregor (2006) : the application of complex training for the development of explosive power, journal of strength and conditioning research , 14(3),pp:360

21. Crielaard, J.M. and Cloes, M(2005)analysis of the volleyball spike journal of sport sciences, London , aug .

22. Ebbn, W.P., et. al 2000 EMG and kinetic analysis of Complex training exercise variables journal of strength and conditioning search.(14)(4)(451-456

23. Duke S. Beneliyohu Achieving strength gains specific to demand of jumping event track coach no. 160 summer, 2002
24. Duthie, G.M., Young, W.B., and Aitken2002 The acute effects of heavy load on jump squat performance on evaluation of the complex and contrast methods of power development.. journal of strength and conditioning research,16(4)530.

25. Factour , I.G.,(2000 Evaluation of plyometiriek exercise training weight vertical jumping and their combination on performance and leg strength. journal of strength and conditioning research.(14)(4)(1470

26. Huana G. chen fui (1993)A biomechanical analysis of volleyball block jumps (jumping), PHD Education, physical, v. 54 O. B. A. Dissertation Abstracts International

27. Radcliff, J.C., Radcliff and J.L.,(1999 Effects of different warm up protocol on peak power. Output during a single response jump task. Medicine and science in sport and exercise.38(5)5189

28. William Ebben David, H. \& Middle, B., (2002: complex training, a brief review, journal of sport science and medicine 1, 42-46, 2002.

29. Wilson,G.J., Murphy, A.J.,(1997 Performance benefits from weigh and plyometric training effects of internal strength coaching and sport science. Journal, Rome 
